This repoyt was prepared as an account of Government sponsored work. Neither the United States, nor the Commission, nor any person acting on behalf of the Commission:

A. Makes any warranty or representation, express or implied, with respect to the accuracy, completeness, or usefulness of the information contained in this report, or that the use of any information, apparatus, method, or process disclosed in this report may not infringe privately owned rights; or

B. Assumes any liabilities with respect to the use of, or for damages resulting from the use of any information, apparatus, method, or process disclosed in this report.

As used in the above, "person acting on behalf of the Commission" includes any employee or contractor of the Commission to the extent that such employee or contractor prepares, handles or distributes, or provides access to, any information pursuant to his employment or contract with the Commission.

\title{
A NUMERICAI INTEGRATION SCHEME FOR PROBLEMS INVOLVING CONTOUR REPRESENTATIONS
}

\author{
C. C. Hudson
}

\begin{abstract}
The definition of the Iebesgue integral is used to develop a numerical integration method in which the integral is evaluated directly from a contour plot of the function. It is useful in working from weather maps, potential surfaces, etc., but was particularly designed to assist in reducing blast diffraction space-time diagrams to simple, meaningful quantities.
\end{abstract}

Case No. 408.01

Photostat Price $\$ 3.30$

Microfilm Price $\$ 2.40$

Available from the

Office of Technical Services

Department of Commerce

Washington 25, D. C. 


\section{DISCLAIMER}

This report was prepared as an account of work sponsored by an agency of the United States Government. Neither the United States Government nor any agency Thereof, nor any of their employees, makes any warranty, express or implied, or assumes any legal liability or responsibility for the accuracy, completeness, or usefulness of any information, apparatus, product, or process disclosed, or represents that its use would not infringe privately owned rights. Reference herein to any specific commercial product, process, or service by trade name, trademark, manufacturer, or otherwise does not necessarily constitute or imply its endorsement, recommendation, or favoring by the United States Government or any agency thereof. The views and opinions of authors expressed herein do not necessarily state or reflect those of the United States Government or any agency thereof. 


\section{DISCLAIMER}

Portions of this document may be illegible in electronic image products. Images are produced from the best available original document. 
DISTRIBUTION:

W. A. MacNair, 5000

S. C. Hight, 5100

E. F. Cox, 5110

R. W. Shephard, 5120

K. W. Erickson, 5130

G. E. Hansche, 5140

H. E. Ienander, 5220

W. C. Scrivner, 5250

M. I. Merritt, 5111

J. D. Shreve, Jr., 5112

G. Owens, 5121

R. H. Thompson, 5251

C. C. Hudson, 5112-1

$R$ and $D$ Files ( 1 )

Max Iinn, $1923(6)<$

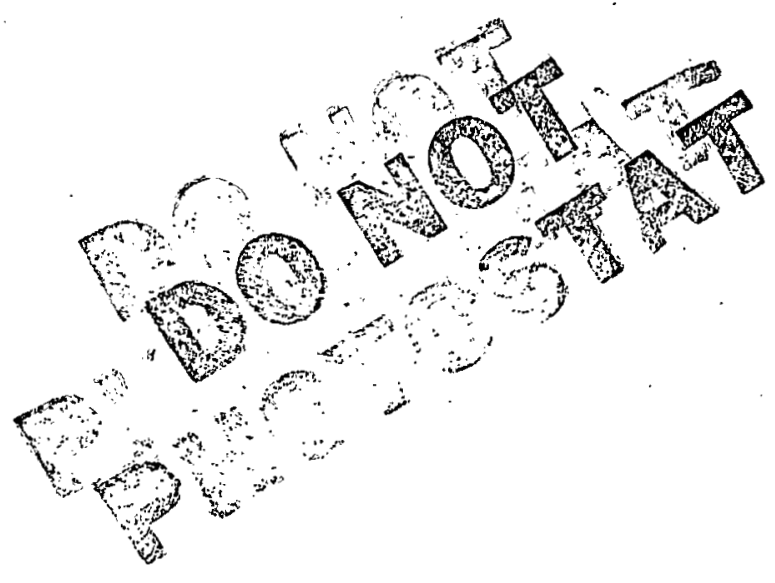




\section{3}

A NUMERICAL INTEGRATION SCHEME FOR PROBIFMS

INVOLVING CONIOUR REPRESENTATIONS

\section{Introduction}

There are some physical measurements which can most conveniently be described by contour representations of the form

$$
\mathrm{Y}_{\mathrm{k}}=\mathrm{f}(\mathrm{U}, \mathrm{V})
$$

where the $Y_{k}$ are values of the function chosen so that

$$
Y_{k+1}=Y_{k}+\text { const. }
$$

Such a representation would be, for example, a weather map ( $Y$ = pressure) or a geographical contour map ( $Y=$ elevation) or an electrical potential map $(Y=$ potential). The independent variables, $U$ and $V$, may both be distance or time and distance or any other two independent physical quantities.

Sometimes we wish to calculate the partial or total integrals over all $U$ and $V$ within the region covered by the experiments. Thus

$$
I_{U}=\int_{a}^{b} f(U, v) d v
$$

where the independent variables may be interchanged, and

$$
I=\int_{a}^{b} \int_{c}^{d} f(U, v) d U d V
$$

Having given the contour map of the function $f(U, \ddot{v})$, we shail proceed to calculate integrals like $I_{U}$ and I directly from the map, making use of the position of the contours.

Example

We are interested in a particular problem, blast diffraction, which may be represented in the contour way; indeed, it was in the study of this problem.that the integration scheme was hit upon." Figure shows a

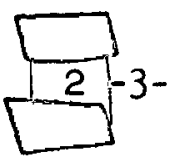


space-time-isobaric diagram that represents the overpressures on the surfaces of a two-dimensional target (Fig. 1) often used for the study of blast loading. The diagram is drawn for a real situation $1 /$ in which the incident shock front struck the target front head-on and, of course, passed normally across the top. A diffracted wave then passed down the back, was reflected at the ground, and returned to the front. All these events are easily discernible in the diagram of Fig. 2. Moreover the vortices that form at the edges are clearly depicted.

Let us specify in detail the coordinates of the representation. Events take place beginning at the leading edge of the target ( $B$ in Figs. $I$ and 2). From this point, waves move away in two directions, down the eront and across the top. Distance (in feet) is measured away from this point (i.e., the leading edge $B$ in the real target is represented by the single point $B$ in the diagram of Fig. 2). Time is measured orthogonally to distance and in Fig. 2 extends to the right. We have arbitrarily chosen the instant of impact of the shock with the leading edge as time zero.

Overpressures were measured along the surface of the target with gauges. In this particular case, 1-psi overpressure differences were considered sufficient detail in which to represent the interaction. The solid curved lines of Fig. 2 are contours of constant overpressure (isobars) and by their locations delineate the diffraction phenomenon.

The dotted lines represent fronts of diffracted waves. These waves travel essentially with the local speed of sound, but their motion relative to the target is modified by the strong fluid motions following the shock. Thus the slopes of the dotted lines give the wave speeds relative to the target. In some instances, these lines are not straight in space-time, indicating unsteady motion. Two dotted lines occur, one on the front and one on the back, which cross the diagram at constant time. These represent the fronts of waves arriving from the ends of the target. A complete discussion of this phenomenon may be found in the Ind Effects Reports. 2,3/ $-4-$ 


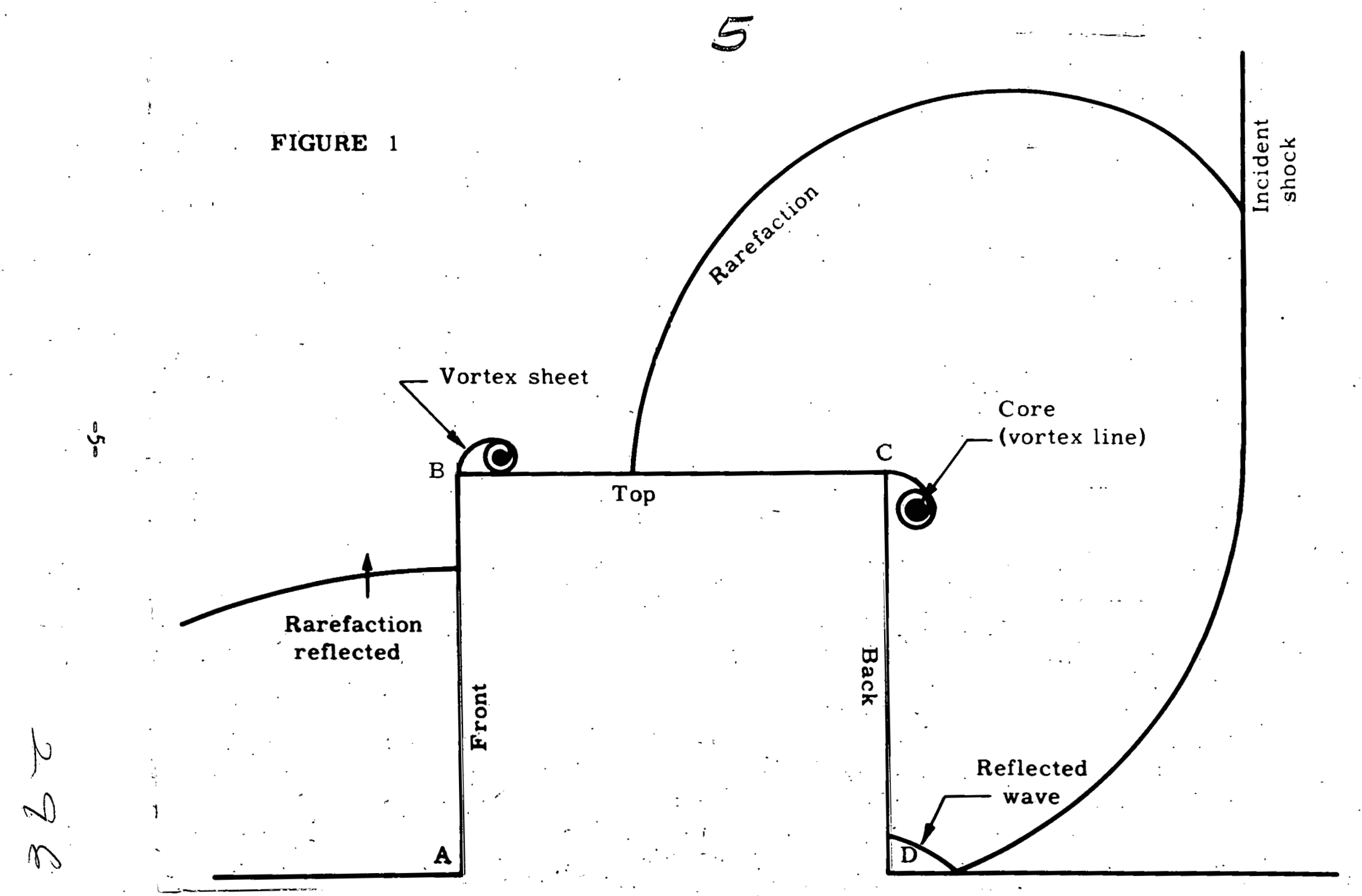



Specification of the Problem

Imagine that one wishes to obtain the average overpressure on front of the target at time $t_{I}$. This can be written

$$
\bar{p}_{t_{1}}=\frac{\int_{x_{1}}^{x_{2}} p(x, t) d x}{\int_{x_{1}}^{x_{2}} d x}
$$

where the integration is performed along the line $t=t_{1}$. We would like to approximate the integral by noting the intersections of this line with the contours. In an analogous way, one might proceed in any direction obtaining such relationships as average overpressure, impulse per square inch, average impulse, etc., not just at select points but throughout the region of space-time occupied by the interaction. The integral to be approximated is analogous to that of Eq. 5 .

The Iebesgue Integral 4/

In searching for an ordinary numerical approximation method for integration, we were continually frustrated by the requirement that for Riemann integrals the independent variable $U$ be disintegrated into a set of numbers such that

$$
\mathrm{U}_{\mathrm{k}+1}=\mathrm{U}_{\mathrm{k}}+\text { const }
$$

which in our case was not possible. A second possibility, that of inverting the roles of dependent and independent variables to get

$$
\mathrm{U}=\mathrm{g}(\mathrm{Y}, \mathrm{V})
$$

was likewise unsuitable, for frequently $g(Y, V)$ would be a multivalued function. 
The Lebesgue integral is defined by disintegrating the $Y$ 's so that Eq. 2 holds. This is indeed just what we need for our purpose. It may be defined, as usual, as the limit of a sum; and in this way, by taking a finite number of terms in the series, we can develop a rudimentary aproximation scheme which is similar to the ordinary trapezoidal rule.

\section{Definition}

Let $f(U)$ represent some relatively well-behaved function of $U$ having only a few discontinuities, and let the area of interest be bounded by $Y_{\max }$ and $Y_{\min }$ (We are being unduly restrictive in the mathematical sense, but physically we can imagine no problems that would not be covered.) Let $E$ represent the set of points $U$, and let $m$ signify "the measure of." Then the Lebesgue integral of $f(U)$ is given by

$$
\int f(U) d U=\lim _{n \rightarrow \infty} \sum_{k=0}^{n-1} Y_{k} m\left\{E\left[Y_{k}<f(U)<Y_{k=1}\right]\right\}
$$

where the region $Y_{\max }-Y_{\min }$ has been separated or decomposed into the set

$$
\mathrm{Y}_{\mathrm{k}+1}=\mathrm{Y}_{\mathrm{k}}+\text { const } \quad 0<\mathrm{k}<\mathrm{n} \text {. }
$$

Equation 8 is to be read: the integral of $f(U)$ is given by the limit of the sum of the product of $Y_{k}$ and the measure of the set of points of $U$ associated with the function $f(U)$ between $Y_{k}$ and $Y_{k+1}$ from $k=0$ to $\mathrm{k}=\mathrm{n}-\mathrm{I}$, taken as $\mathrm{n}$ becomes indefinitely large. For the relatively simple case we have outlined here, "the measure of" may be read "the sum of", and the set of points $E$ may be taken as the projection of $f(U)$ between $Y_{k+l}$ and $Y_{k}$ onto the $U$-axis. By removing the limit sign, we obtain a fairly good approximation formula

$$
\int f(U) d U \approx \sum_{k=0}^{n-1} Y_{k} m\left\{E\left[y_{k}<f(U)<y_{k+I}\right]\right\}
$$


which is restricted in accuracy only by the magnitude of $\mathrm{n}$ relative to variation of $f(U)$.

We have limited ourselves so far only to the region $Y_{k}>0$. The irtegral is defined for $-\infty<\mathrm{Y}_{\mathrm{k}}<+\infty$ and we shall proceed now to make isse of this more general form.

\section{Tleveloping the Approximation Formula}

To tie down our ideas more concretely, let us develop a working formula from Eq. 9. Consider the plot of $Y=f(U)$ shown in Fig. 3. The function is limited by $Y_{\max }$ and $Y_{\min }$, and the region $Y_{\max }-Y_{\min }$ is divided here into 8 equal parts which satisfy $\mathrm{Eq} .2$. Let the lines $Y=Y_{k}$ be drawn; then the "measure" of the set of points in $U$ corresponding to $Y_{4}<f(U)<Y_{3}$ is, as an example, equal to $\left(U_{6}-U_{5}\right)+\left(U_{4}-U_{3}\right)$. It is obvious that, as we consider all the subregions $Y_{k+1}-Y_{k}$, the entire function will be covered and, in fact, will be covered only once. Iet us now write down the whole sum for the particular case of Fig. 3 . We get

$$
\begin{aligned}
& \int_{U_{0}}^{U_{m}} f(U) d U=Y_{0}\left\{\left(U_{1}-U_{0}\right)+\left(U_{11}-U_{10}\right)\right\}+Y_{1}\left\{\left(U_{2}-U_{1}\right)\right. \\
+ & \left.\left(U_{8}-U_{7}\right)+\left(U_{10}-U_{9}\right)\right\}+Y_{2}\left\{\left(U_{3}-U_{2}\right)+\left(U_{7}-U_{6}\right)+\left(U_{9}-U_{8}\right)\right\} \\
+ & Y_{3}\left\{\left(U_{4}-U_{3}\right)+\left(U_{6}-U_{5}\right)\right\}+Y_{4}\left\{U_{5}-U_{4}\right\}+Y_{-1}\left\{U_{12}-U_{11}\right\} \\
+ & Y_{-2}\left\{U_{m}-U_{12}\right\} .
\end{aligned}
$$

Rearranging terms gives

$$
\begin{aligned}
& -\mathrm{U}_{0} \mathrm{Y}_{0}-\Delta \mathrm{YU}_{1}-\Delta \mathrm{YU}_{2}-\Delta \mathrm{YU}_{3}-\Delta \mathrm{YU}_{4}+\Delta \mathrm{YU}_{5}+\Delta \mathrm{YU}_{6} \\
& +\Delta \mathrm{YU}_{7}-\Delta \mathrm{YU}_{8}+\Delta \mathrm{YU}_{9}+\Delta \mathrm{YU}_{10}+\Delta \mathrm{YU}_{11}+\Delta \mathrm{YU}_{12}+\mathrm{Y}_{-2} \mathrm{U}_{\mathrm{m}}
\end{aligned}
$$


where

$$
\Delta \mathrm{Y}=\mathrm{Y}_{\mathrm{k}+1}-\mathrm{Y}_{\mathrm{k}} \quad \mathrm{Y}_{\mathrm{k}+1}>\mathrm{Y}_{\mathrm{k}}
$$

It is immaterial whether or not we take $U_{0}$ to be zero, but if we do, the first term drops out. Notice that the sign of each term is the negative of the sign of the slope at that particular point. Thus, since the particular nature of $f(U)$ did not enter, other than to determine the signs of the terms, we may generalize and infer the working formula.

$$
\int_{U_{0}}^{U_{m}} f(U) d U \approx \Delta Y \sum_{k}\left(I_{k}\right)+Y_{m} U_{m} \cdot
$$

where $Y_{m}$ corresponds to $U_{m}$. The sum is understood to be over $k$ whether it ranges from $-\infty$ to $+\infty$ or from 0 to $+\infty$.

One notes that the use of Eq. 9 with finite $n$ might be expected to lead to rather large errors. This appears in Fig. 4 where the lightly shaded portion shows the integral as computed by Eq. 9 which is patently too small. A restatement of Eq. 9 with $Y_{k+1}$ in place of the $Y_{k}$ outside the brace would, by shifting all entries $\Delta \mathrm{Y}$, overestimate and yield errors. similar in magnitude. A mean value approach, giving a shift of $\Delta \mathrm{Y} / 2$, suggests itself as a way to refine the approximation; the resulting form is

$$
\int f(U) d U=\sum_{k} 1 / 2\left(Y_{k+1}+Y_{k}\right) m\left\{E\left[Y_{k}<f(U)<Y_{k+1}\right]\right\}
$$

from which the working formula becomes

$$
\int_{0}^{U_{m}} f(U) d U \approx \Delta Y \sum_{k}\left( \pm U_{k}\right)+1 / 2\left(Y_{m}+Y_{m+1}\right) U_{m} .
$$

Note the significance of $Y_{m}$ and $Y_{m+1}$ by understanding that at $U_{m}$ the value of the function $f\left(U_{m}\right)$ lies between $Y_{m}$ and $Y_{m+l}$. For the case shown in Fig. 3, $1 / 2\left(Y_{m}+Y_{m+1}\right) U_{m}=1 / 2\left(Y_{-2}+Y_{-1}\right) U_{m}$. 
The only explicit change mathematically is in the last or "correction" term. Seen graphically, the influence of the change is very satisfying. Specifically, the new area brought into the integral for finite $n$ is given by the cross-hatched region in Fig. 4. Notice that the basic definition of the Lebesgue integral is not altered because the difference between $Y_{k}$ and $1 / 2\left(Y_{k+1}+Y_{k}\right)$ is insignificant in the limit as $n \rightarrow \infty$, yet for the usual instances of interest (finite $n$ ) Eq. 12a is obviously a better formula to use than Eq. 12 .

\section{Error Estimation}

We know that the function lies between $Y_{k+l}$ and $Y_{k}$ and we have chosen finally to approximate $i$ ts position by $1 / 2\left(Y_{k+1}+Y_{k}\right)$. The maximum possible error is therefore given by the difference between Eqs. 12a and 12 . This turns out to be

$$
U_{m}\left[1 / 2\left(Y_{m}+Y_{m-1}\right)-Y_{m}\right] .
$$

In other words,

$$
\text { Error } \leq 1 / 2 \Delta \mathrm{YU}_{\mathrm{m}}
$$

which says that, for a given function, the error goes as $1 / 2 \Delta Y$ : the more closely spaced the isobars, the smaller $\Delta Y$ and the more accurate the calculation.

\section{Applicability to Machine Computations}

The integration procedure outlined above may be very conveniently used with a desk-type calculator. First, the line along which the summation is to be made is marked in some way, perhaps by the edge of a transparent rule. Then, beginning at one edge of the region of interest and taking it as zero, the intersection of the rule with each contour is noted, read, and the value punched into the computer. When the next to the last entry has been made, the sum is taken and multiplied by $\Delta Y$; 


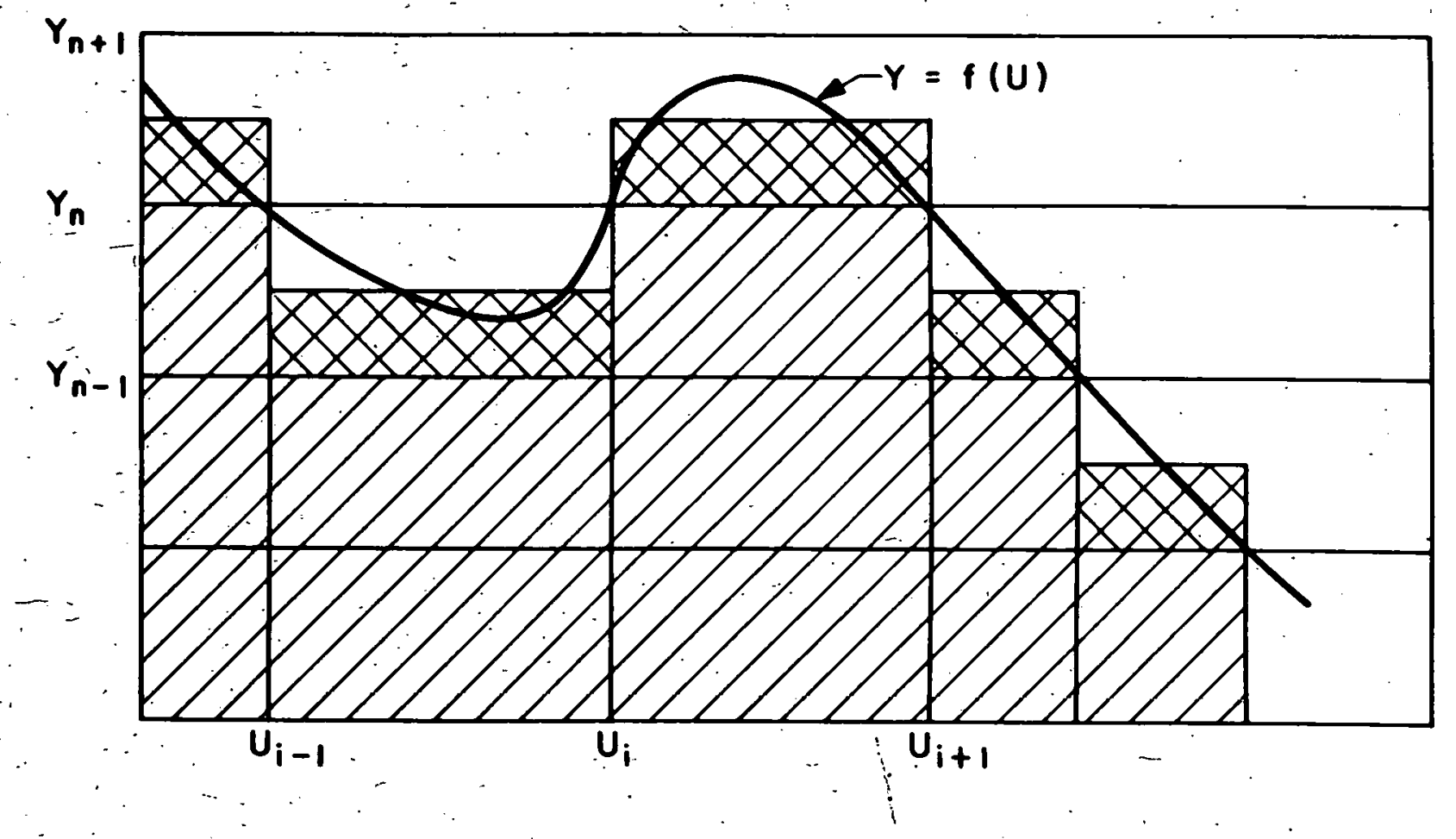

FIGURE 4

$-13-$ 
finally the last term is added on. The procedure is very rapid in the hands of a trained operator and double integrals can be computed by the summing of a single series.

\section{Accuracy}

Let us call the accuracy of the method $G$ (for goodness) and write

$$
G \geq 1 \text { - relative error }
$$

where the relative error is given by

$$
\frac{1 / 2 \Delta U_{m}}{\Delta Y \sum_{k}\left( \pm U_{k}\right)+1 / 2\left(Y_{m}+Y_{m+1}\right) U_{m}}
$$

which may be written

$$
\frac{1}{2 \sum_{k}\left( \pm U_{k}\right)+\frac{Y_{m}}{\Delta Y}}
$$

where $Y_{m}$ approximates $1 / 2\left(Y_{m}+Y_{m+l}\right)$. Obviously $G \rightarrow I$ as $\Delta Y \rightarrow 0$ but it is not possible to estimate $G$ without first computing $\sum\left( \pm \mathrm{J}_{k}\right)$. In general, however, the accuracy is poorer for oscillating functions than for monotonic functions.

Some numerical examples may help to tie down the idea of accuracy. The integral of $12 \sin 2 \pi \mathrm{U}$ was computed from 0 to $1 / 2$ with $\Delta Y$ equal to 1 , 2 , and 4. The errors relative to the true value of the integral were .01 , .02 , and .04 , respectively. Also the integral

$$
\int_{0}^{t}\left(1-t / t_{+}\right) e^{-t / t} d t
$$


was evaluated with $\Delta Y=. I$ from the table

$$
\begin{array}{cc}
f(t) & t / t_{t} \\
1.00 & .000 \\
.90 & .052 \\
.80 & .108 \\
.70 & .168 \\
.60 & .238 \\
.50 & .314 \\
.40 & .402 \\
.30 & .502 \\
.20 & .624 \\
.10 & .778 \\
.00 & 1.000
\end{array}
$$

and is given by

$$
\begin{aligned}
& {[0.1(.052+.108+.168+.238+.314+.402+.502+.624+.778)} \\
& +1 / 2(.1+0)] t_{+}=.369 t_{+},
\end{aligned}
$$

whereas the exact value of the integral is $t_{+} / e$ or $0.368 t_{+}$, an error of less than $I$ per cent. Notice that the correction term $I / 2\left(Y_{m}+Y_{m-I}\right) U_{m}$ becomes merely $I / 2 \Delta U_{m}$ when the function ends at zero.

C. C. HUDSON - 5112

Case No. 408.01

July 6, 1955 


\section{REFERENICES}

1. Merritt, M. I., Some Tests of the Diffraction of Blast Waves, Sandia Corporation report SC-1803(TR), June 7, 1951.

2. Hudson, C. C., Blast Loading End Effects I, AFSWP 461, August 24, 1954.

3. Hudson, C. C., Blast Loading End Effects II, AFSWP 462, to be published.

4. W. W. Rogosinski, Volume and Integral, University Mathematical Texts, Interscience Publishers, Inc. (N.Y.) (1952) Theorem 84, p. 121. 


$$
1-16
$$

THIS PAGE

\author{
WAS INTENTIONALLY \\ LEFT BLANK
}


